\title{
Surviving a Catastrophic Upper Gastrointestinal Bleeding Caused by Esophageal-Subclavian Fistula: Case Report
}

\author{
Khalid Y. Nabrawi', Mohamed-Elbagir K. Ahmed ${ }^{2}$, Abdulrahman Y. Asiri ${ }^{1}$, Shaima M. Al-Aoun ${ }^{1}$, \\ Abdullah M. Alshehri' ${ }^{1}$ Abdullah H. Alhaizaey ${ }^{1}$, Musaad A. Alghamdi ${ }^{1}$, Ali S. Alahmari ${ }^{1}$ \\ ${ }^{1}$ Aseer Central Hospital, Abha, Saudi Arabia \\ ${ }^{2}$ King Khalid University, Saudi Arabia \\ Email: *mohamedelbagir@live.com
}

How to cite this paper: Nabrawi, K.Y., Ahmed, M.-E.K., Asiri, A.Y., Al-Aoun, S.M., Alshehri, A.M., Alhaizaey, A.H., Alghamdi, M.A. and Alahmari, A.S. (2018) Surviving a Catastrophic Upper Gastrointestinal Bleeding Caused by Esophageal-Subclavian Fistula: Case Report. Open Journal of Gastroenterology, 8, 209-212.

https://doi.org/10.4236/ojgas.2018.86023

Received: May 16, 2018

Accepted: June 19, 2018

Published: June 22, 2018

Copyright $(0) 2018$ by authors and Scientific Research Publishing Inc. This work is licensed under the Creative Commons Attribution International License (CC BY 4.0).

http://creativecommons.org/licenses/by/4.0/

\begin{abstract}
Arterio-esophageal fistula (AEF), whether congenital or acquired, is a rare condition which can lead to fatal upper gastrointestinal bleeding. We report here a young man who developed a subclavian-esophageal fistula (SEF) secondary to chicken bone impaction in the upper esophagus. The diagnosis was reached by urgent upper endoscopy and Computed Tomography of the chest which showed pseudo-aneurysmal changes at left subclavian artery with leaked contrast through the fistula towered the esophagus. Urgent endo-vascular angiography confirmed the subclavian arterio-esophageal fistula that was managed uneventfully using covered $6 \mathrm{~mm}$ Viban stent-graft. The patient survived this serious condition and was discharged home in good condition.
\end{abstract}

\section{Keywords}

Gastrointestinal Bleeding, Esophageal-Subclavian Fistula

\section{Introduction}

Bleeding from an arterio-esophageal fistula (AEF) is a rare and mostly fatal condition. The first case of aorto-esophageal Fistula was described by the French naval surgeon Dubreuil in 1818 [1]. Although this arises from an aberrant subclavian artery in most of occasions, it can result as a complications of foreign body impaction in the upper esophagus leading to an esophageal-aortic or esophageal-subclavian fistula in a normal anatomy setting [2] [3] [4]. Generally, this condition should be suspected if a patient reported difficulty in swallowing, massive vomiting of blood, or underwent recent aortic or esophageal surgery [1]. 
Chiari and colleagues published the first AEF due to boney food impaction in 1914 and described the specific symptoms that constituted a specific syndrome [5]. However, few cases of non-aberrant left subclavian AEF caused by foreign body impaction were reported [1] [6], and most of such patients succumbed to massive bleeding. Here we document one patient who survived a massive upper gastrointestinal bleeding caused by a left subclavian artery esophageal fistula induced by chicken bone impaction. Fortunately, this serious complication was discovered early and well managed by endovascular stent grafting [6] [7].

\section{Patient Presentation}

A previously well 16-year-old man who had experienced food impaction following a chicken meal presented to the emergency department complaining of discomfort at the root of the neck associated with difficulty in swallowing. The patient was discharged from the ED after normal chest and neck X-rays.

However, he returned back 6 days later with retrosternal discomfort and difficulty in swallowing, as well as having had few episodes of vomiting bright red blood, the last one of these was a large volume bleed.

Examination revealed that he was unstable with sinus tachycardia of $10^{5} / \mathrm{min}$, hypotension at 100/60, pallor, and clinical sign of hypovolemic shock. The rest of the examination was unremarkable His hemoglobin was $6.6 \mathrm{md} / \mathrm{dl}(14-17$ gm./dl) with normal biochemistry and INR (normal $<1.1$ ) The patient was admitted to the intensive care unit and resuscitated with 6 units packed RBCs.

Urgent upper gastro-intestinal endoscopy showed traumatic ulceration at upper third of esophagus around $17 \mathrm{~cm}$ from incisor with sign of chronic changes suspicious of foreign body injury.

Urgent Computed Tomography of the chest with arterial phase contrast revealed a left subclavian-esophageal traumatic fistula with pseudo-aneurysmal changes of the left subclavian artery and demonstrated the leaked contrast through the fistula towards the esophagus (Figures 1(a)-(b)). Urgent endovascular angiography confirmed the subclavian arterio-esophageal fistula that was managed uneventfully using covered $6 \mathrm{~mm}$ Viban stent-graft (Figure 2).

The patient improved dramatically with obvious stabilization of his clinical signs and his hemoglobin increased to $14 \mathrm{~g} / \mathrm{dl}$ with complete resolution of bleeding.

He was discharged 48 hours post management on good clinical condition and remained well on regular clinic follow-up after 2 weeks, then after $3 \& 6$ months.

\section{Discussion}

As described by Chiari, Arterio-esophageal (AEF) syndrome consists of initial esophageal injury followed by a symptom-free interval preceding the "signal bleeding," and finally culminating in exsanguinating hemorrhage hours or days later [5]. The patient presented here exhibits a similar course to what was described in the literature. He initially complained of difficulty of swallowing after 


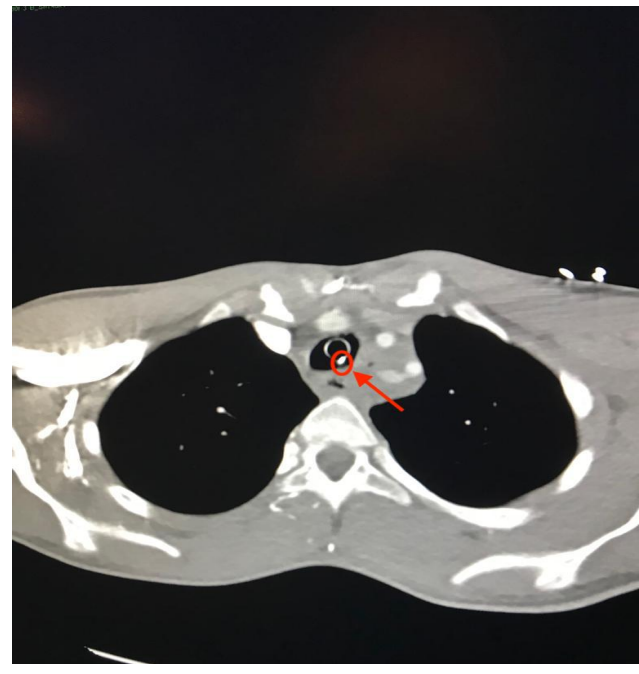

(a)

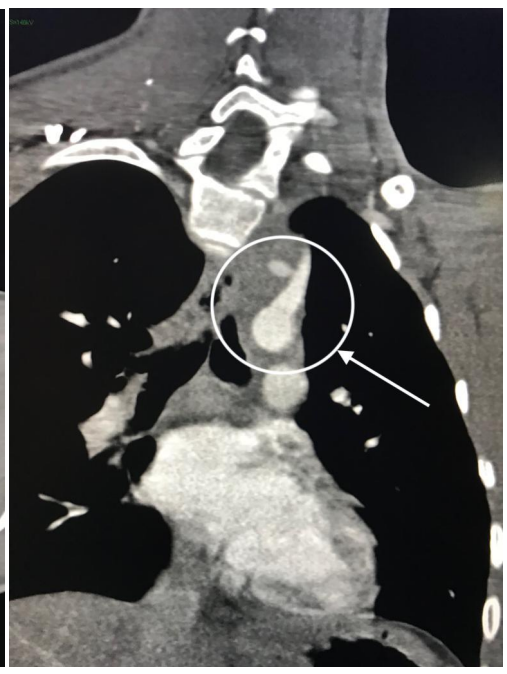

(b)

Figure 1. (a) CT scan showing the clip inserted initially to control the bleeding (arrow); (b) Sagittal view computed tomography of chest showed pseudo-aneurysmal changes at left subclavian artery with leaked contrast through the fistula towered the esophagus (arrow).

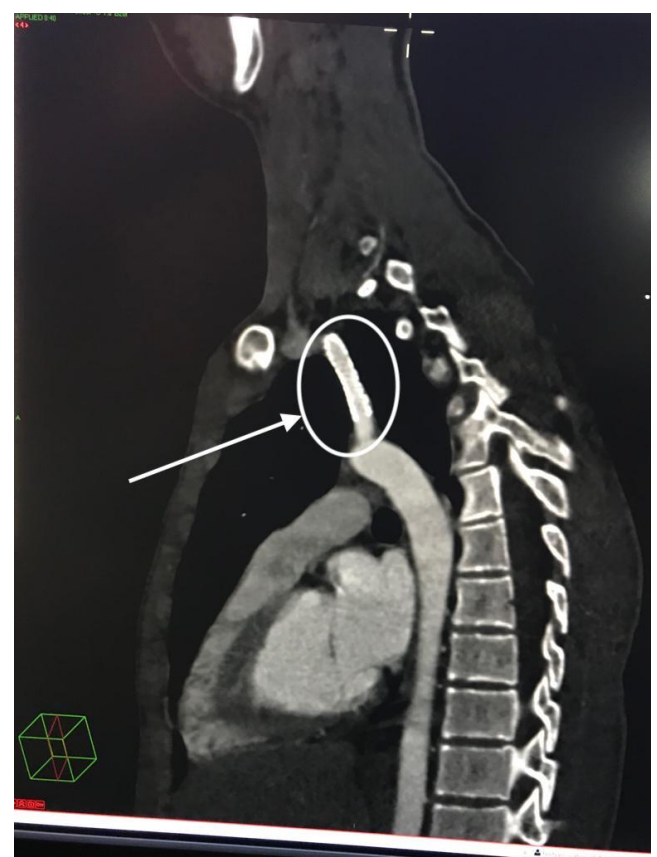

Figure 2. Sagittal view computed tomography of chest showing the stent-graft (arrow).

he ingested a bony chicken meal, and then he remained stable for few days. After that, he started to vomit blood (the index bleed) which ended up with a massive upper gastrointestinal bleeding.

Over the past years, more than hundred cases of AEF secondary to foreign body ingestion have been documented but only few, including our patient, have survived for months [4] [6]. Floréa reported a similar patient to ours, but involving an infected fistula [7]. Most of the cases of AEF occurred about $1-5 \mathrm{~cm}$ from the origin of the left subclavian artery which is explained by the narrowing 
of the esophagus secondary to food impaction [5]. In contrast to most reported cases, our patient has normal anatomy of the subclavian artery and thanks to the early diagnosis \& intervention, he survived this serious event [7].

The currently accepted management comprises vascular stent-graft interposition and if no success, this can be followed by esophageal surgery and mediastinal drainage. Fortunately, our patient did not need open thoracic surgery which usually carries a high mortality [8] [9] [10].

\section{Conclusion and Recommendations}

Arterio-esophageal fistula secondary to food impaction is rare but is life-threatening and should be discovered early by Computed Tomography imaging if suspected. The key message to be learned from this report is to exercise a high index of suspicion for AEF fistula in patients presenting with difficulty in swallowing or vomiting of blood after taking a bone-containing meal, or who ingest a sharp foreign body. This is because early recognition contributes to a better prognosis following relevant workup and subsequent management with endovascular stent grafting, or open thoracic surgery.

\section{References}

[1] Dubreuil, J.M. (1818) Observation sur la perforation de l'oesophage et de I'aorte thoracique par une portion d'os avale: avec des reflexions. J Univ Sci Med, 9, 357.

[2] Millar, A., Rostom, A., Rasuli, P. and Saloojee, N. (2007) Upper Gastrointestinal Bleeding Secondary to an Aberrant Right Subclavian Artery-Esophageal Fistula: A Case Report and Review of the Literature. Canadian Journal of Gastroenterology, 21, 389-392. https://doi.org/10.1155/2007/398213

[3] Mok, C.K., Chiu, C.S. and Cheung, H.H. (1989) Left Subclavian Arterioesophageal Fistula Induced by a Foreign Body. The Annals of Thoracic Surgery, 47, 458-460. https://doi.org/10.1016/0003-4975(89)90395-0

[4] Kelly, S.L., Peters, P., Ogg, M.J., Li, A. and Smithers, B.M. (2009) Successful Management of an Aortoesophageal Fistula Caused by a Fish Bone-Case Report and Review of Literature. Journal of Cardiothoracic Surgery, 4, 21. https://doi.org/10.1186/1749-8090-4-21

[5] Chiari, H. (1914) About Fremdkorpeverletzung of the Esophagus with Aorto-Perforation. Berlin. Klin Wochenschr, 51, 7-9.

[6] Hollander, J.E. and Quick, G. (1991) Aortoesophageal Fistula: A Comprehensive Review of the Literature. The American Journal of Medicine, 91, 279-287. https://doi.org/10.1016/0002-9343(91)90129-L

[7] Floré, B., Heye, S., Nafteux, P. and Maleux, G. (2014) Single-Stage Endovascular Treatment of an Infected Subclavian Arterio-Oesophagal Fistula. European Journal of Cardio-Thoracic Surgery, 45, 570-572. https://doi.org/10.1093/ejcts/ezt324

[8] Ctercteko, G. and Mok, C.K. (1980) Aorta-Esophageal Fistula Induced by a Foreign Body. The First Recorded Survival. The Journal of Thoracic and Cardiovascular Surgery, 80, 233.

[9] Poulet, A. (1880) A Treatise on Foreign Bodies in Surgical Practice. Vol 1. William Wood \& Co, New York.

[10] Le Roux, B.T. (1964) Intrathoracic Foreign Bodies. Thorax, 19, 203. https://doi.org/10.1136/thx.19.3.203 